\title{
Phase II study of bevacizumab, cisplatin, and docetaxel plus maintenance bevacizumab as first-line treatment for patients with advanced non-squamous
} non-small-cell lung cancer combined with exploratory analysis of circulating endothelial cells: Thoracic Oncology Research Group (TORG) 1016

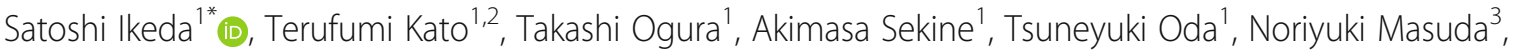
Satoshi Igawa ${ }^{3}$, Ken Katono ${ }^{3}$, Sakiko Otani ${ }^{3}$, Kouzo Yamada ${ }^{2}$, Haruhiro Saito ${ }^{2}$, Tetsuro Kondo ${ }^{2}$, Yukio Hosomi ${ }^{4}$, Yoshiro Nakahara ${ }^{3,4}$, Masanori Nishikawa ${ }^{5}$, Keiko Utumi ${ }^{6}$, Yuki Misumi ${ }^{7}$, Takeharu Yamanaka ${ }^{8}$,

Kentaro Sakamaki ${ }^{8}$ and Hiroaki Okamoto ${ }^{7}$

\begin{abstract}
Background: Preclinical studies have demonstrated that docetaxel and bevacizumab may act synergistically by decreasing endothelial cell proliferation and preventing circulating endothelial progenitor mobilization. The objective of this study was to assess the efficacy and safety of a combination therapy of bevacizumab, cisplatin, and docetaxel in chemotherapy-naive Japanese patients with advanced non-squamous non-small-cell lung cancer (NSCLC).

Methods: Eligible patients were chemotherapy-naive and had advanced/recurrent non-squamous NSCLC. The patients received 4 cycles of docetaxel $\left(60 \mathrm{mg} / \mathrm{m}^{2}\right)$, cisplatin $\left(80 \mathrm{mg} / \mathrm{m}^{2}\right)$, and bevacizumab $(15 \mathrm{mg} / \mathrm{kg})$ once every 3 weeks, followed by bevacizumab as maintenance therapy, every 3 weeks until disease progression or attainment of unacceptable toxicity level. The primary endpoint was objective response rate (ORR). The numbers of circulating endothelial cells (CEC) were also estimated on days 1 and 8 of the first cycle for the exploratory analysis of efficacy prediction.

(Continued on next page)
\end{abstract}

\footnotetext{
* Correspondence: isatoshi0112@gmail.com

${ }^{1}$ Department of Respiratory Medicine, Kanagawa Cardiovascular and

Respiratory Center, Tomioka-Higashi 6-16-1, Kanazawa-ku, Yokohama, Japan

Full list of author information is available at the end of the article
} 


\begin{abstract}
(Continued from previous page)
Results: A total of 47 patients were enrolled from October 2010 to April 2012. Bevacizumab as maintenance therapy was administered to 41 patients (87.2\%), and the median number of total treatment cycles was 9 (range: 1-36). ORR, median progression-free survival (PFS), and median overall survival of the patients were 74.5\%, 9.0 months, and 27. 5 months, respectively. The most common grade $3 / 4$ adverse event was neutropenia (95.7\%), followed by leukopenia (59.6\%) and hypertension (46.8\%). PFS was longer in patients with $\geq 10$ count increase in CECs than that in patients with $<10$ count increase in CECs (respective median PFS of 11.0 months versus 6.90 months) although the difference was not statistically significant ( $p=0.074)$.
\end{abstract}

Conclusions: A combination therapy of bevacizumab, cisplatin, and docetaxel, followed by bevacizumab as maintenance was highly effective in patients with non-squamous NSCLC despite the high incidence of grade 3/4 neutropenia. The increase in CEC count between days 1 and 8 may predict the efficacy of our bevacizumab-contained treatment regimen.

Trial registration: UMIN Clinical Trial Registry; UMIN000004368. Registered date; October 11, 2010 (Retrospectively registered).

Keywords: Non-small cell lung cancer, Docetaxel, Bevacizumab, Circulating endothelial cell,

\section{Background}

Among the platinum-based doublet chemotherapy for patients with advanced non-small-cell lung cancer (NSCLC), docetaxel is one of the best taxane composition combined with cisplatin [1]. The cytotoxic activity of docetaxel is mainly exerted by promoting the assembly of microtubules from tubulin dimers, which in turn, inhibits the depolymerization of tubulin that stabilizes microtubules in the cells [2-4]. This results in the inhibition of DNA, RNA, and protein synthesis. In addition, docetaxel inhibits vascular endothelial growth factor (VEGF)-induced neovascularization in vivo and has an anti-angiogenic effect [5, 6]. Furthermore, the blockade of the VEGF pathway has emerged as a rational target for therapeutic intervention owing to the dependence of tumor survival and growth on angiogenesis. In recent phase III studies, Bevacizumab, a humanized monoclonal antibody that inhibits VEGF, in combination with platinum-based chemotherapy has been reported to increase both objective response rates (ORRs) and progression-free survival (PFS) in chemotherapy-naive patients with advanced NSCLC $[7,8]$. Although carboplatin/paclitaxel has often been selected along with bevacizumab, preclinical studies have revealed that docetaxel decreases endothelial cell proliferation, thereby increasing the efficacy of VEGF receptor blockade by bevacizumab [9]. In addition, bevacizumab prevents the mobilization of circulating endothelial progenitors, which are induced from the bone marrow by vascular disrupting agents, such as docetaxel, and contributes to tumor angiogenesis and growth [10]. To date, two single-arm phase II studies of bevacizumab $(15 \mathrm{mg} / \mathrm{kg})$, docetaxel $\left(75 \mathrm{mg} / \mathrm{m}^{2}\right)$, and cisplatin as the first-line treatment for patients with metastatic non-squamous NSCLC have revealed an acceptable toxicity profile and promising anti-tumor effect [11, 12]. However, the Japanese population appears to be more susceptible to the toxicity of docetaxel, and the approved docetaxel dose for NSCLC is $60 \mathrm{mg} / \mathrm{m}^{2}$ in Japan [13]. The efficacy and safety of $60 \mathrm{mg} / \mathrm{m}^{2}$ of docetaxel combined with bevacizumab and cisplatin in Japanese patients should be confirmed. Furthermore, it is critically important to establish biomarkers that can identify subgroups of patients who can benefit from bevacizumab for the improvement of clinical outcome and treatment costs. The change in the number of circulating endothelial cells (CECs) before cancer treatment and that after the administration of drugs has been reported to be a potential biomarker for the prediction of response to bevacizumab [14].

The objective of this study was to assess the efficacy and safety of bevacizumab, cisplatin, and docetaxel in a combination treatment regimen for chemotherapy-naive Japanese patients with non-squamous NSCLC. In addition, CECs were evaluated for the exploratory analysis of efficacy prediction.

\section{Methods \\ Study design}

This multi-center, single-arm, phase II study was conducted in accordance with the Declaration of Helsinki and the Ethical Guidelines for Clinical Research issued by the Japanese Ministry of Health, Labour and Welfare. The anticipated trial start date was October 1, 2010, and the data cutoff date was October 1, 2014. The protocol was approved by the Clinical Trial Review Committee of the Thoracic Oncology Research Group (TORG) and the Institutional Review Board or Ethics Committee of each participating center. All patients provided written informed consent. This study adheres to CONSORT guidelines.

\section{Study participants}

The inclusions criteria for the study subjects were as follows: (1) pathologically or cytologically confirmed NSCLC; (2) stage IIIA/IIIB/IV unsuitable for curative radiotherapy 
or post-operative recurrent disease; (3) age $\geq 20$ years and $\leq 75$ years; (4) Eastern Cooperative Oncology Group (ECOG) performance status (PS) of 0 or 1 ; (5) at least one measurable lesion meeting the Response Evaluation Criteria (RECIST) (version 1.1); (6) no prior treatment except for surgery, epidermal growth factor receptor tyrosine kinase inhibitor (EGFR-TKI), and palliative radiotherapy; (7) adequate organ function (white blood cell count $\geq 4000$ cells $/ \mu \mathrm{L}$, neutrophil count $\geq 2000$ cells $/ \mu \mathrm{L}$, hemoglobin $\geq 9.0 \mathrm{~g} / \mathrm{dL}$, platelet count $\geq 100,000$ cells $/ \mu \mathrm{L}$, aspartate aminotransferase (AST) and alanine aminotransferase (ALT) levels $\leq 100 \mathrm{IL} / \mathrm{L}$, total bilirubin level $\leq 1.5 \mathrm{mg} / \mathrm{dL}$, serum creatinine level $\leq 1.2 \mathrm{mg} / \mathrm{dL}$, creatinine clearance level $\geq$ $60 \mathrm{~mL}$, oxygen saturation by pulse oximetry $\geq 93 \%$, proteinuria $\leq 1+)(8)$ life expectancy $>3$ months; (9) adequate interval after prior treatments ( 2 weeks from radiotherapy, 8 weeks from lobectomy, 4 weeks from exploratory thoracotomy, and 2 weeks from pleural drainage); and (10) written informed consent. The exclusion criteria for the study subjects were as follows: (1) presence of brain metastases, (2) history of hemoptysis, (3) severe or uncontrollable comorbidities, (4) massive pleural/pericardial effusion or ascites, (5) concomitant malignancy, (6) history of peptic ulcer within the past year, or (7) regular use of anticoagulants ( $\leq 325 \mathrm{mg} /$ day of aspirin was permitted).

\section{Treatment}

The patients received 4 cycles of docetaxel $\left(60 \mathrm{mg} / \mathrm{m}^{2}\right.$, intravenously administered over a period of $1 \mathrm{~h}$ ), cisplatin $\left(80 \mathrm{mg} / \mathrm{m}^{2}\right.$, intravenously administered over a period of $2 \mathrm{~h}$ ), and bevacizumab $(15 \mathrm{mg} / \mathrm{kg}$, intravenously administered over a period of $1.5 \mathrm{~h}$ ) once every 3 weeks, followed by bevacizumab alone as maintenance therapy every 3 weeks until disease progression or the attainment of unacceptable toxicity.

\section{Evaluation}

Tumor response was evaluated by the Extramural Central Review Committee according to the RECIST. PFS was assessed from the date of enrollment to the development of the earliest sign of disease progression, as determined by chest computed tomography (CT) or magnetic resonance imaging (MRI) according to RECIST criteria, or death from any cause. Overall survival (OS) was assessed from the date of enrollment until death from any cause. Safety was assessed according to the National Cancer Institute Common Terminology Criteria for Adverse Events (CTCAE; version 3.0). Disease status was assessed by a chest CT or MRI every 6 weeks. After the confirmation of partial response (PR), the patients underwent a chest CT or MRI every 4 weeks until disease progression.

\section{Statistical analysis}

The primary end point of the study was ORR. Based on the Simon's two-staged design, the planned sample size of 47 patients was determined appropriate to reject a null ORR of 35\% at one-sided significance level of 0.05 under an expected ORR of $55 \%$ with a power of 0.80 . The secondary end points included OS, PFS, and safety. All patients were followed-up until October 1, 2014. Cumulative survival probabilities were estimated using the Kaplan-Meier method. A log-rank test was performed to compare survival among the patient groups. A $p<0.05$ was considered statistically significant. Statistical analyses were performed using SAS Version 9.3.1.

\section{Analysis of CECs}

The CEC counts were determined on days 1 and 8 of the first cycle for the exploratory analysis of efficacy prediction using the CellSearch ${ }^{\circ}$ system. This system is composed of a combination of semiautomatic isolation of CECs and microscopic visualization based on immunophenotypical and morphological definitions. The blood sample $(10 \mathrm{ml})$ is first collected into a CellSave $^{\mathrm{Tx}}$ tube, which contains a solution of Na2EDTA and a cell preservative. After blood collection, the cells expressing cluster of differentiation (CD) 146 are immunomagnetically captured using ferrofluids coated with anti-CD146 monoclonal antibodies. The enriched cells are then labeled with 4',6-diamidino-2-phenylindole, CD105 and CD45. CECs were defined when its morphological features are consistent with that of a cell and it exhibits the correct phenotypes (positive for CD146, CD105 and 4',6-diamidino-2-phenylindole, negative for hematopoietic marker CD45). Results are reported as the number of CECs per $4.0 \mathrm{~mL}$ of blood.

\section{Results \\ Baseline characteristics}

A total of 47 patients [28 males and 19 females (59.6\%); median age, 61 years; age range, 39-73 years] were enrolled from 7 centers across Japan from October 2010 to April 2012. Patient demographics and disease characteristics are summarized in Table 1. All patients presented with adenocarcinoma, and 39 patients $(83.0 \%)$ had stage-IV disease. The ECOG-PS score was 0 in $31 \mathrm{pa-}$ tients (66.0\%) and 1 in 16 patients (34.0\%). EGFR mutations were detected in 13 patients (27.7\%).

\section{Treatment delivery and efficacy}

A total of 44 patients (93.6\%) received 4 cycles of cisplatin, docetaxel, and bevacizumab, and 41 patients $(87.2 \%)$ received $\geq 1$ cycle of maintenance bevacizumab. The median number of total treatment cycles was 9 (range: 1-21). Cisplatin dose reduction was required in 13 patients (27.7\%), and docetaxel dose reduction was 
Table 1 Baseline characteristics of the study population

\begin{tabular}{ll}
\hline & $N=47$ \\
\hline Age & $61(39-73)$ \\
Smoking history & $28 / 19$ \\
ECOG Performance Status & $33(70.2 \%)$ \\
0 & $31 / 16$ \\
1 & $31(66.0 \%)$ \\
Histology & $16(34.0 \%)$ \\
adenocarcinoma & \\
Staging & $47(100 \%)$ \\
IIIB & \\
IV & $5(10.6 \%)$ \\
recurrent & $39(83.0 \%)$ \\
EGFR mutation & $3(6.4 \%)$ \\
wild type & \\
exon19 deletion & $32(68.1 \%)$ \\
exon21 L858R & $7(15.2 \%)$ \\
exon21 L858R + de novo T790 M & $5(10.9 \%)$ \\
unknown & $1(2.1 \%)$ \\
Prior treatment & $2(4.2 \%)$ \\
surgery & \\
EGFlliative radiotherapy tyrosine kinase inhibitor & $3(6.4 \%)$ \\
\hline AbbrevatonsECOG & $3(6.4 \%)$ \\
\hline & 0 \\
\hline
\end{tabular}

Abbreviations: $E C O G$ eastern cooperative oncology group, EGFR epidermal growth factor receptor

required in 12 patients (25.5\%). A total of 35 patients (74.5\%) achieved partial responses with an ORR of $74.5 \%$ [95\% confidence interval (CI): 59.7-86.1\%]. Eleven patients (23.4\%) archived a stable disease status with a disease control rate of 97.9\% (95\% CI: 88.7-99.9\%). Median PFS was 9.0 (95\% CI: 7.0-11.3) months (Fig. 1). PFS rate

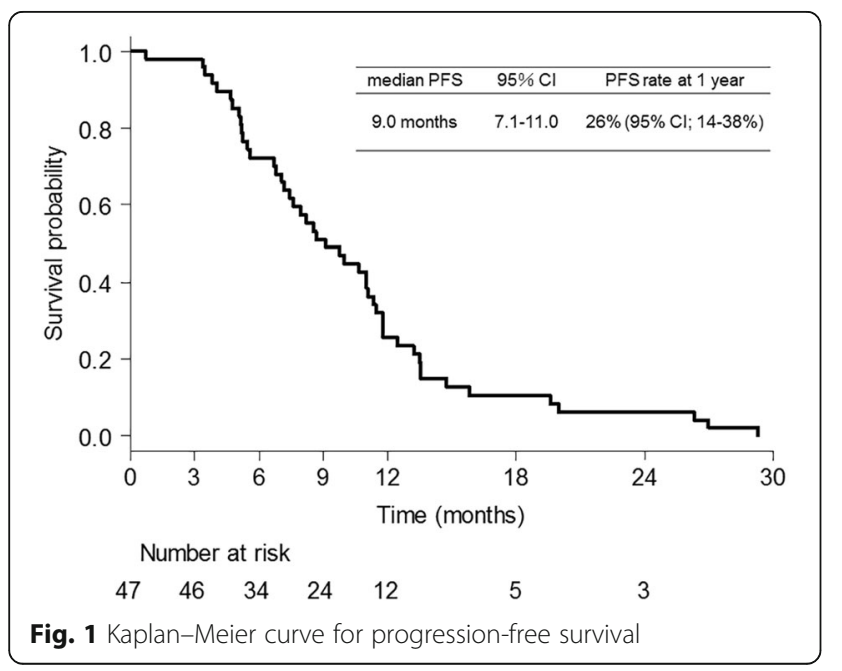

at 1 year was 26\% (95\% CI: 14-38\%). Median OS was 27.5 (95\% CI: 21.1-32.9) months (Fig. 2). OS rate at 1 year was 94\% (95\% CI: 82-98\%).

\section{Adverse events (AEs)}

Hematological and non-hematological toxicities of all patients are summarized in Table 2. The most common grade $\geq 3 \mathrm{AE}$ in the induction therapy was neutropenia (95.7\%), followed by leukopenia (59.6\%), hypertension $(31.9 \%)$, anorexia $(12.8 \%)$, nausea $(12.8 \%)$, and febrile neutropenia (8.5\%). One patient $(2.1 \%)$ developed alveolar hemorrhage (Grade 5) after 4 cycles of induction therapy [15]. During the maintenance therapy of bevacizumab $(N=41)$, the grade $\geq 3 \mathrm{AE}$ was rarely observed, except for hypertension (34.1\%).

\section{Analysis of CECs}

In 35 patients, CEC count was measured on days 1 and 8 (Additional file 1: Figure S1; Additional file 2: Table S1). CECs increased to $\geq 10$ count in 15 patients (42.9\%) from the baseline to day 8. Survival curves were compared on the basis of the change from baseline to day 8 (Fig. 3). PFS was longer in patients with $\geq 10$ count increase in CECs than in patients with $<10$ count increase in CECs (respective median PFS of 11.0 months and 6.90 months, respectively) although the difference was not statistically significant $(p=0.074)$.

\section{Discussion}

The present study demonstrated three important clinical observations. First, the combined therapy of bevacizumab, cisplatin, and docetaxel, followed by bevacizumab maintenance treatment revealed high efficacy in patients with advanced non-squamous NSCLC. Second, a high frequency of grade $\geq 3$ neutropenia and leukopenia were observed although the other AEs were almost manageable. Third, PFS was longer in patients with $\geq 10$ count

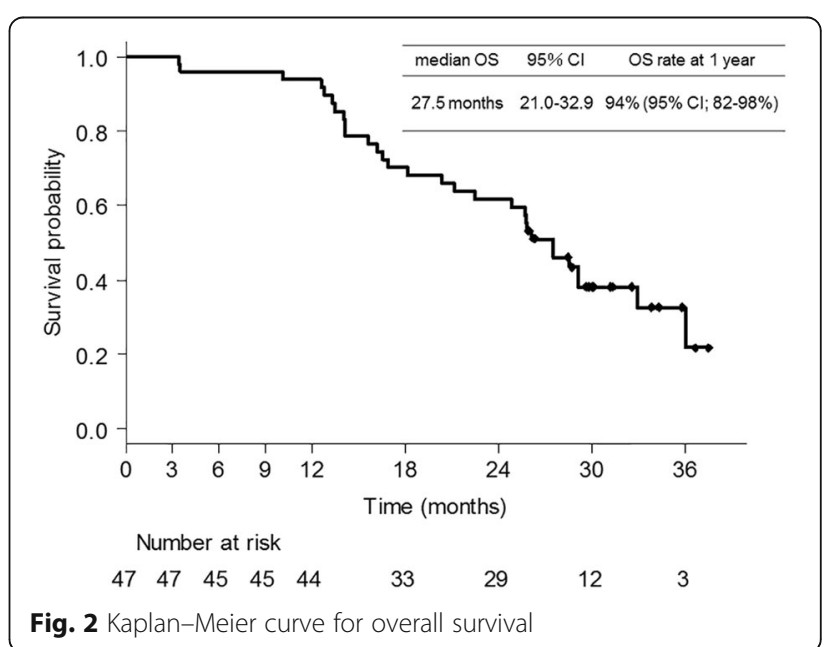


Table 2 Adverse events during induction and maintenance phases

\begin{tabular}{|c|c|c|c|c|}
\hline & \multicolumn{2}{|c|}{$\begin{array}{l}\text { Induction phase: } 1-4 \text { cycles } \\
(N=47)\end{array}$} & \multicolumn{2}{|c|}{$\begin{array}{l}\text { Maintenance phase: } 5 \text { cycles- } \\
(N=41)\end{array}$} \\
\hline & All grade & Grade $\geq 3$ & All grade & Grade $\geq 3$ \\
\hline Leukopenia & $46(97.8 \%)$ & $28(59.6 \%)$ & $4(9.8 \%)$ & 0 \\
\hline Neutropenia & $46(97.8 \%)$ & 45 (95.7\%) & $2(4.9 \%)$ & 0 \\
\hline Febrile neutropenia & $4(8.5 \%)$ & $4(8.5 \%)$ & 0 & 0 \\
\hline Anemia & 47 (100\%) & $2(4.3 \%)$ & $27(65.9 \%)$ & 0 \\
\hline Thrombocytopenia & $27(57.4 \%)$ & 0 & $7(17.1 \%)$ & 0 \\
\hline Hypoalbuminemia & $43(91.5 \%)$ & 0 & $7(17.1 \%)$ & 0 \\
\hline AST increased & $12(25.5 \%)$ & 0 & $7(17.1 \%)$ & 0 \\
\hline ALT increased & $17(36.2 \%)$ & $1(2.1 \%)$ & $5(12.2 \%)$ & 0 \\
\hline ALP increased & $18(37.3 \%)$ & 0 & $8(19.5 \%)$ & 0 \\
\hline Creatinine increased & $25(53.2 \%)$ & 0 & $17(41.5 \%)$ & 0 \\
\hline Anorexia & $43(91.5 \%)$ & $6(12.8 \%)$ & $3(7.3 \%)$ & 0 \\
\hline Nausea & 39 (83.0\%) & $6(12.8 \%)$ & $4(9.8 \%)$ & 0 \\
\hline Vomiting & $13(27.7 \%)$ & 0 & 0 & 0 \\
\hline Diarrhea & $17(36.2 \%)$ & $3(6.4 \%)$ & $2(4.9 \%)$ & 0 \\
\hline Constipation & $19(40.4 \%)$ & 0 & $2(4.9 \%)$ & 0 \\
\hline Weight loss & $27(57.4 \%)$ & 0 & $8(19.5 \%)$ & 0 \\
\hline Fatigue & $24(51.1 \%)$ & 0 & $6(14.6 \%)$ & 0 \\
\hline Alopecia & $38(80.9 \%)$ & 0 & $19(46.3 \%)$ & 0 \\
\hline Oral mucositis & $10(21.3 \%)$ & 0 & $1(2.4 \%)$ & 0 \\
\hline Sensory neuropathy & $8(17.0 \%)$ & 0 & $10(24.4 \%)$ & 0 \\
\hline Fever & $7(14.9 \%)$ & $1(2.1 \%)$ & $2(4.9 \%)$ & 0 \\
\hline Hypertension & $44(93.6 \%)$ & 15 (31.9\%) & 34 (82.9\%) & $14(34.1 \%)$ \\
\hline Proteinuria & $32(68.1 \%)$ & 0 & $13(31.7 \%)$ & 0 \\
\hline Nasal bleeding & $9(19.1 \%)$ & 0 & $5(12.2 \%)$ & 0 \\
\hline
\end{tabular}

Abbreviations: $A S T$ aspartate aminotransferase, $A L T$ alanine aminotransferase, $A L P$ alkaline phosphatase

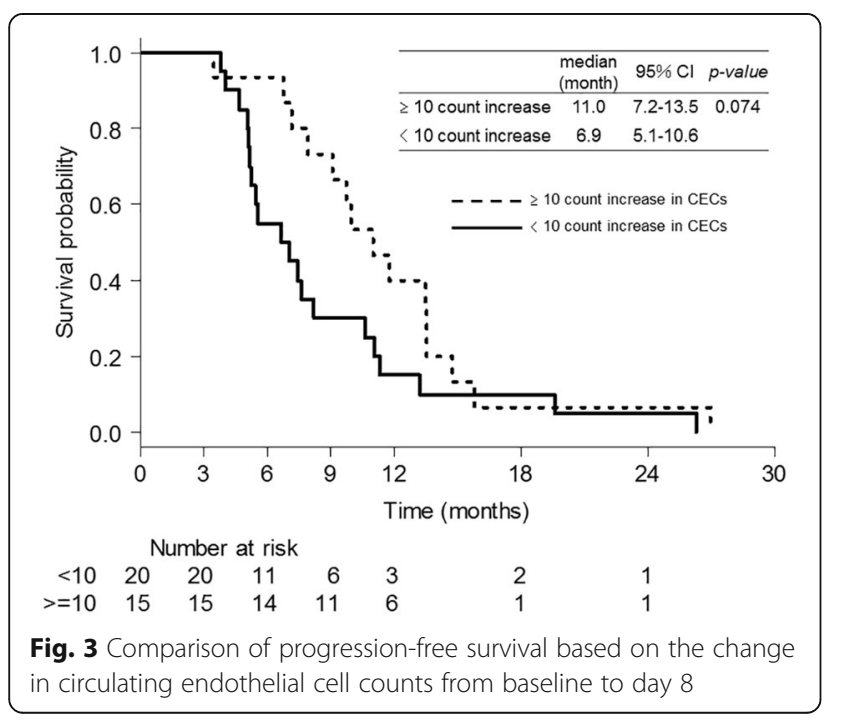

increase in CECs than in patients with $<10$ count increase in CECs.

The past two single-arm phase II studies of bevacizumab $(15 \mathrm{mg} / \mathrm{kg})$ in combination with docetaxel $(75 \mathrm{mg} /$ $\left.\mathrm{m}^{2}\right)$ and cisplatin $\left(75 \mathrm{or} 80 \mathrm{mg} / \mathrm{m}^{2}\right)$ as the first-line treatment of patients with metastatic non-squamous NSCLC have revealed favorable anti-tumor effect, with an ORR of 33.3-63.0\%, a median PFS of 4.4-7.8 months, and a median OS of 13.3-13.5 months [11, 12]. Despite the use of Japanese reduced dose of docetaxel $\left(60 \mathrm{mg} / \mathrm{m}^{2}\right)$, the present study revealed much higher ORR and much longer PFS and OS than in the above-mentioned past two studies and the past studies using other third generation chemotherapy plus platinum with bevacizumab, such as E4599, AVAiL, AVAPERL and PointBreak trials [7, 8, 16, 17]. These results suggest that the anti-tumor effect of cisplatin, docetaxel, and bevacizumab combination therapy is extremely promising. Furthermore, these results also suggested that the present regimen may be more effective for Japanese patients. When comparing global phase 3 study 
(E4599 trial) and Japanese phase 2 study (JO19907 trial) of carboplatin, paclitaxel and bevacizumab combination therapy, Japanese trial revealed higher ORR and longer PFS than global trial $[7,18]$. Similarly, when comparing global phase 3 study (REVEL trial) and Japanese phase 2 bridging study (JVCG trial) of docetaxel plus ramucirumab, a monoclonal antibody that inhibits VEGFR-2, Japanese trial revealed higher ORR and longer PFS than global trial despite Japanese reduced dose of docetaxel $[19,20]$. It was speculated that there may be an ethnic difference in the efficacy of taxanes and angiogenesis inhibitors combination therapy.

In terms of toxicity, neutropenia and leukopenia were the most common AEs among grade $\geq 3$ AEs in the past phase II studies of cisplatin, docetaxel, and bevacizumab (grade $\geq 3$ neutropenia occurred in $18.7-22.0 \%$ patients and grade $\geq 3$ leukopenia in $8.4-9.8 \%$ patients, respectively) $[11,12]$. However, in the present study, the incidence of neutropenia and leukopenia was higher than in the past two studies, despite the use of Japanese reduced dose of docetaxel $\left(60 \mathrm{mg} / \mathrm{m}^{2}\right)$. According to the past phase III trials of docetaxel monotherapy, grade $\geq 3$ neutropenia was more frequently observed in Japanese patients treated with $60 \mathrm{mg} / \mathrm{m}^{2}(73.3-85.9 \%)$ than in the patients from the Western countries treated with $75 \mathrm{mg} /$ $\mathrm{m}^{2}$ dose (21-37\%) although the efficacy was almost equivalent in both the cases [21-29]. The results of the phase III trials with docetaxel $\left(60 \mathrm{mg} / \mathrm{m}^{2}\right)$ plus cisplatin in Japanese patients with advanced NSCLC have revealed that the incidence of grade $\geq 3$ neutropenia and leukopenia was $73.4-74.2 \%$ and $45.7-55.2 \%$, respectively $[30,31]$. Moreover, randomized phase II trial of docetaxel versus docetaxel plus bevacizumab in Japanese patients with NSCLC, who were previously treated with bevacizumab plus a platinum-based doublet, has demonstrated that additional bevacizumab increased the incidence of grade $\geq 3$ leukopenia and neutropenia [32]. These results suggest that severe neutropenia and leukopenia are the most serious AEs of the present regimen. Nevertheless, in this study, non-hematological toxicities were almost manageable, the transfer rate to the bevacizumab maintenance therapy was high, and the number of treatment cycles was more than in other studies. The prophylactic use of pegylated granulocyte colony-stimulating factor ensures the higher safety of this promising regimen.

To date, no useful biomarker has been established for predicting the efficacy of bevacizumab. CECs are mature endothelial cells that are sloughed from the vessel wall, and increase in CECs in the peripheral blood is expected to serve as a potential biomarker for predicting response to bevacizumab [14, 33-35]. Because the CEC counts appear to vary according to the type of cancer or the types of assay methods, the usefulness of CECs remains controversial. However, several studies have suggested that change in the CEC count after chemotherapy serves as a predictive biomarker for the effect of chemotherapy, particularly for bevacizumab combination therapy. Calleri et al. [14] have reported that tumor progression under bevacizumab-combined chemotherapy was associated with a significant CEC count decrease in advanced breast cancer patients [14]. In addition, Bidard et al. [36] have reported that in breast cancer patients receiving bevacizumab combination with taxane-based therapy, increase in the CEC count during treatment was associated with improved time to disease progression, whereas the baseline CEC counts were not associated with time to progression. CECs are thought to represent an indirect marker of vascular remodeling and turnover [37], thus, it was speculated that increase in CEC reflects the degree of regression or normalization of existing tumor vasculature and the inhibition of new and recurrent tumor vessel growth by bevacizumab. Regarding patients with advanced NSCLC, there has been no prospective study of a bevacizumab-containing regimen that evaluated the correlation between the change in CEC count and treatment efficacy. Therefore, it is important to accumulate more cases from a number of hospitals to further validate the findings of the present study.

This study had some limitations. First, the lack of a standard assay for CEC counting may hinder the clinical application of the proposed concept in clinical practice. However, the variability in $\mathrm{CEC}$ values is smaller among studies that measure CECs by CellSearch ${ }^{\circ}$ than those that use other systems. Second, 11 of 13 patients with EGFR-sensitive mutations received EGFRtyrosine kinase inhibitor as a second- or third-line treatment, which warrants a careful interpretation of the evaluated OS values.

\section{Conclusions}

Bevacizumab, cisplatin, and docetaxel in combination, followed by bevacizumab alone as a maintenance treatment was highly effective in patients with non-squamous NSCLC despite the high incidence of grade 3/4 neutropenia. The increases in CECs count between days 1 and 8 may predict the efficacy of our bevacizumab-contained treatment regimen.

\section{Additional files}

Additional file 1: Figure S1. Trial profile. Abbreviations: CEC, circulating endothelial cell. (JPEG $147 \mathrm{~kb}$ )

Additional file 2: Table S1. CEC data and treatment efficacy of 35 patients whose CEC count was measured on days 1 and 8. Abbreviations: EGFR, epidermal growth factor receptor; CEC, circulating endothelial cell; PR, partial response; SD, stable disease; PFS, progression-free survival; OS, overall survival. (DOCX $22 \mathrm{~kb}$ ) 


\section{Abbreviations}

AEs: Adverse events; ALT: Alanine aminotransferase; AST: Aspartate aminotransferase; CD: Cluster of differentiation; CEC: Circulating endothelial cell; Cl: Confidence interval; CT: Computed tomography; CTCAE: Common terminology criteria for adverse events; ECOG: Eastern cooperative oncology group; EGFR: Epidermal growth factor receptor; MRI: Magnetic resonance imaging; NSCLC: Non-small cell lung cancer; ORR: Objective response rates; PFS: Progression-free survival; PR: Partial response; PS: Performance status; RECIST: Response evaluation criteria; TKI: Tyrosine kinase inhibitor; TORG: Thoracic oncology research group; VEGF: Vascular endothelial growth factor

\section{Acknowledgements}

The authors would like to thank Fumiaki Koizumi (Division of Clinical Research Support, Tokyo Metropolitan Cancer and Infectious Diseases Center, Komagome Hospital, Tokyo, Japan.) for the measurement of CECs and their advice concerning the CEC analysis.

\section{Funding}

This research received no specific grant from any funding agency in the public, commercial, or not-for-profit sectors.

\section{Availability of data and materials}

The datasets generated during and/or analyzed during the current study are available from the corresponding author on reasonable request.

\section{Authors' contributions}

KT1 (second author), OT1 (third author), and $\mathrm{OH}$ developed study concepts and design. IS1 (first/corresponding author), KT1, OT1, SA, OT2 (fifth author), MN, IS2 (seventh author), KK, OS, YK, SH, KT2 (twelfth author), HY, NY, NM, UK, MY, and $\mathrm{OH}$ were acquired data acquisition; $Y T$ and SK were involved in the quality control of data and algorithms. IS1, KT1, OT1, SA, OT2, MN, IS2, KK, OS, YK, SH, KT2, HY, NY, NM, UK, MY, YT, SK, and OH were involved in the analysis and interpretation of the clinical data. $Y T$ and SK were involved in the statistical analysis. IS1, KT1, and SA were involved in drafting the manuscript. OT1, OT2, MN, IS2, KK, OS, YK, SH, KT2, HY, NY, NM, UK, MY, YT, $\mathrm{SK}$, and $\mathrm{OH}$ were involved in revising the manuscript. All authors have read and approved the final manuscript.

\section{Ethics approval and consent to participate}

The protocol was approved by the Clinical Trial Review Committee of the Thoracic Oncology Research Group and the Institutional Review Board or Ethics Committee of Kanagawa Cardiovascular and Respiratory Center, Kanagawa Cancer Center, Kitasato University Hospital, Tokyo Metropolitan Cancer and Infectious Diseases Center Komagome Hospital, Fujisawa City Hospital, Ibaraki Prefectural Central Hospital, and Yokohama Municipal Citizen's Hospital. All patients provided written informed consent.

\section{Consent for publication}

Not applicable.

\section{Competing interests}

Ikeda S, Ogura T, Sekine A, Oda T, Igawa S, Katono K, Otani S, Yamada K, Saito H, Kondo T, Nishikawa M, and Sakamaki K declare no potential conflicts of interest with any companies/organizations, whose products or services may be discussed in this article. Kato T received honoraria from Chugai Pharmaceutical, Roche, Boehringer Ingelheim Japan, Ono Pharmaceutical, Eli Lilly Japan, AstraZeneca, Taiho Pharmaceutical, Pfizer Japan, and Kyowa Hakko Kirin. Masuda N has received honoraria from Pfizer Japan, Bristol Myers Squibb, and Ono Pharmaceutical. Hosomi $Y$ and Nakahara $Y$ received honoraria from Chugai Pharmaceutical. Yamanaka T received honoraria from Chugai Pharmaceutical, Takeda Pharmaceutical, Boehringer Ingelheim, Taiho Pharmaceutical, and research funds from Takeda Pharmaceutical and Taiho Pharmaceutical. Okamoto $\mathrm{H}$ received honoraria from Takeda Pharmaceutical, MSD, Ono Pharmaceutical, Astrazeneca, Merck, Chugai Pharmaceutical, Taiho Pharmaceutical, Bristol Myers Squibb, Eli Lilly Japan, and Daiich Sankyo.

\section{Publisher's Note}

Springer Nature remains neutral with regard to jurisdictional claims in published maps and institutional affiliations.

\section{Author details}

'Department of Respiratory Medicine, Kanagawa Cardiovascular and Respiratory Center, Tomioka-Higashi 6-16-1, Kanazawa-ku, Yokohama, Japan. ${ }^{2}$ Department of Thoracic Oncology, Kanagawa Cancer Center, Yokohama, Japan. ${ }^{3}$ Department of Respiratory Medicine, Kitasato University Hospital, Sagamihara, Japan. ${ }^{4}$ Division of Thoracic Oncology and Respiratory Medicine, Tokyo Metropolitan Cancer and Infectious Diseases Center Komagome Hospital, Tokyo, Japan. ${ }^{5}$ Department of Respiratory Medicine, Fujisawa City Hospital, Fujisawa, Japan. ${ }^{6}$ Department of Respiratory Medicine, Ibaraki Prefectural Central Hospital, Kasama, Japan. ${ }^{7}$ Department of Respiratory Medicine and Medical Oncology, Yokohama Municipal Citizen's Hospital, Yokohama, Japan. ${ }^{8}$ Department of Biostatistics, Yokohama City University School of Medicine, Yokohama, Japan.

Received: 27 October 2017 Accepted: 19 February 2018

Published online: 02 March 2018

\section{References}

1. Schiller JH, Harrington D, Belani CP, Langer C, Sandler A, Krook J, et al. Comparison of four chemotherapy regimens for advanced non-small-cell lung cancer. N Engl J Med. 2002;346:92-8.

2. Yvon AM, Wadsworth $P$, Jordan MA. Taxol suppresses dynamics of individual microtubules in living human tumor cells. Mol Biol Cell. 1999;10:947-59.

3. Lyseng-Williamson KA, Fenton C. Docetaxel: a review of its use in metastatic breast cancer. Drugs. 2005;65:2513-31.

4. Eisenhauer EA, Vermorken JB. The taxoids. Comparative clinical pharmacology and therapeutic potential. Drugs. 1998;55:5-30.

5. Klauber N, Parangi S, Flynn E, Hamel E, D'Amato RJ. Inhibition of angiogenesis and breast cancer in mice by the microtubule inhibitors 2-methoxyestradiol and taxol. Cancer Res. 1997;57:81-6.

6. Belotti D, Vergani V, Drudis T, Borsotti P, Pitelli MR, Viale G, et al. The microtubule-affecting drug paclitaxel has antiangiogenic activity. Clin Cancer Res. 1996:2:1843-9.

7. Sandler A, Gray R, Perry MC, Brahmer J, Schiller JH, Dowlati A, et al. Paclitaxel-carboplatin alone or with bevacizumab for non-small-cell lung cancer. N Engl J Med. 2006;355:2542-50.

8. Reck M, von Pawel J, Zatloukal P, Ramlau R, Gorbounova V, Hirsh V, et al. Phase III trial of cisplatin plus gemcitabine with either placebo or bevacizumab as first-line therapy for nonsquamous non-small-cell lung cancer: AVAil. J Clin Oncol. 2009;27:1227-34.

9. Sweeney CJ, Miller KD, Sissons SE, Nozaki S, Heilman DK, Shen J, et al. The antiangiogenic property of docetaxel is synergistic with a recombinant humanized monoclonal antibody against vascular endothelial growth factor or 2-methoxyestradiol but antagonized by endothelial growth factors. Cancer Res. 2001;61:3369-72.

10. Yuval S, Erik H, Jeanine R, Mancuso P, Langenberg $\mathrm{MH}$, Colleoni M, et al. Rapid chemotherapy-induced acute endothelial progenitor cell mobilization: implications for antiangiogenic drugs as chemosensitizing agents. Cancer Cell. 2008;14:263-73.

11. Ferrer N, Cobo M, Paredes A, Torrego J. Phase II study of bevacizumab $(15 \mathrm{mg} / \mathrm{kg})$ in combination with cisplatin $(75 \mathrm{mg} / \mathrm{m} 2)$ and docetaxel $(75 \mathrm{mg} / \mathrm{m} 2)$ as first-line treatment of patients (p) with metastatic nonsquamous non-small cell lung cancer (NSCLC). J Clin Oncol. 2009;27:e19023.

12. Kentepozidis N, Kotsakis A, Soultati A, Agelaki S, Christophylakis C, Agelidou $\mathrm{M}$, et al. Docetaxel plus cisplatin and bevacizumab for untreated patients with advanced/metastatic non-squamous non-small-cell lung cancer: a multicenter phase II study of the Hellenic Oncology Research Group. Cancer Chemother Pharmacol. 2013;71:605-12.

13. Kunitoh $H$, Watanabe $K$, Onoshi T, Furuse K, Niitani $H$, Taguchi T, et al. Phase II trial of docetaxel in previously untreated advanced non-small-cell lung cancer: a Japanese cooperative study. J Clin Oncol. 1996;14:1649-55.

14. Calleri A, Bono A, Bagnardi V, Quarna J, Mancuso P, Rabascio C, et al. Predictive potential of angiogenic growth factors and circulating endothelial cells in breast cancer patients receiving metronomic chemotherapy plus bevacizumab. Clin Cancer Res. 2009;15:7652-7.

15. Ikeda S, Sekine A, Kato T, Yoshida M, Ogata R, Baba T, et al. Diffuse alveolar hemorrhage as a fatal adverse effect of bevacizumab: an autopsy case. Jpn J Clin Oncol. 2014:44:497-500.

16. Barlesi F, Scherpereel A, Rittmeyer A, Pazzola A, Ferrer Tur N, Kim JH, et al. Randomized phase III trial of maintenance bevacizumab with or without pemetrexed after first-line induction with bevacizumab, cisplatin, and 
pemetrexed in advanced nonsquamous non-small-cell lung cancer: AVAPERL (MO22089). J Clin Oncol. 2013;31:3004-11.

17. Patel JD, Socinski MA, Garon EB, Reynolds CH, Spigel DR, Olsen MR, et al. PointBreak: a randomized phase III study of pemetrexed plus carboplatin and bevacizumab followed by maintenance pemetrexed and bevacizumab versus paclitaxel plus carboplatin and bevacizumab followed by maintenance bevacizumab in patients with stage IIIB or IV nonsquamous non-small-cell lung cancer. J Clin Oncol. 2013;31:4349-57.

18. Niho S, Kunitoh H, Nokihara H, Horai T, Ichinose $Y$, Hida T, et al. Randomized phase II study of first-line carboplatin-paclitaxel with or without bevacizumab in Japanese patients with advanced non-squamous nonsmall-cell lung cancer. Lung Cancer. 2012;76:362-7.

19. Garon EB, Ciuleanu TE, Arrieta O, Prabhash K, Syrigos KN, Goksel T, et al. Ramucirumab plus docetaxel versus placebo plus docetaxel for second-line treatment of stage IV non-small-cell lung cancer after disease progression on platinum-based therapy (REVEL): a multicentre, double-blind, randomised phase 3 trial. Lancet. 2014:384:665-73.

20. Yoh K, Hosomi Y, Kasahara K, Yamada K, Takahashi T, Yamamoto N, et al. A randomized, double-blind, phase II study of ramucirumab plus docetaxel vs placebo plus docetaxel in Japanese patients with stage IV non-small cell lung cancer after disease progression on platinum-based therapy. Lung Cancer. 2016;99:186-93.

21. Maruyama R, Nishiwaki Y, Tamura T, Yamamoto N, Tsuboi M, Nakagawa K, et al. Phase III study, V-15-32, of gefitinib versus docetaxel in previously treated Japanese patients with non-small-cell lung cancer. J Clin Oncol. 2008;26:4244-52.

22. Paz-Ares L, Ross H, O'Brien M, Riviere A, Gatzemeier U, Von Pawel J, et al. Phase III trial comparing paclitaxel poliglumex vs docetaxel in the secondline treatment of non-small-cell lung cancer. Br J Cancer. 2008;98:1608-13.

23. Takeda K, Negoro S, Tamura T, Nishiwaki Y, Kudoh S, Yokota S, et al. Phase III trial of docetaxel plus gemcitabine versus docetaxel in second-line treatment for non-small-cell lung cancer: results of a Japan Clinical Oncology Group trial (JCOG0104). Ann Oncol. 2009;20:835-41.

24. Krzakowski M, Ramlau R, Jassem J, Szczesna A, Zatloukal P, Von Pawel J, et al. Phase III trial comparing vinflunine with docetaxel in second-line advanced non-small-cell lung cancer previously treated with platinumcontaining chemotherapy. J Clin Oncol. 2010;28:2167-73.

25. Herbst RS, Sun Y, Eberhardt WE, Germonpré P, Saijo N, Zhou C, et al. Vandetanib plus docetaxel versus docetaxel as second-line treatment for patients with advanced non-small-cell lung cancer (ZODIAC): a doubleblind, randomised, phase 3 trial. Lancet Oncol. 2010;11:619-26.

26. Ramlau R, Gorbunova V, Ciuleanu TE, Novello S, Ozguroglu M, Goksel T, et al. Aflibercept and docetaxel versus docetaxel alone after platinum failure in patients with advanced or metastatic non-small-cell lung cancer: a randomized, controlled phase III trial. J Clin Oncol. 2012;30:3640-7.

27. Garassino MC, Martelli O, Broggini M, Farina G, Veronese S, Rulli E, et al. Erlotinib versus docetaxel as second-line treatment of patients with advanced non-small-cell lung cancer and wild-type EGFR tumors (TAILOR): a randomised controlled trial. Lancet Oncol. 2013:14:981-8.

28. Kawaguchi T, Ando M, Asami K, Okano Y, Fukuda M, Nakagawa H, et al. Randomized phase III trial of erlotinib versus docetaxel as second- or third-line therapy in patients with advanced non-small-cell lung cancer: Docetaxel and Erlotinib Lung Cancer Trial (DELTA). J Clin Oncol. 2014;32:1902-8.

29. Reck M, Kaiser R, Mellemgaard A, Douillard JY, Orlov S, Krzakowski M, et al. Docetaxel plus nintedanib versus docetaxel plus placebo in patients with previously treated non-small-cell lung cancer (LUME-lung 1): a phase 3, double-blind, randomised controlled trial. Lancet Oncol. 2014;15:143-55.

30. Kubota K, Watanabe K, Kunitoh $\mathrm{H}$, et al. Phase III randomized trial of docetaxel plus cisplatin versus vindesine plus cisplatin in patients with stage IV non-small-cell lung cancer: the Japanese Taxotere Lung Cancer Study Group. J Clin Oncol. 2004;22:254-61.

31. Kubota K, Sakai H, Katakami N, Noda K, Ichinose Y, Katakami N, et al. A randomized phase III trial of oral S-1 plus cisplatin versus docetaxel plus cisplatin in Japanese patients with advanced non-small-cell lung cancer: TCOG0701 CATS trial. Ann Oncol. 2015;26:1401-8.

32. Takeda M, Yamanaka T, Seto T, Hayashi H, Azuma K, Okada M, et al. Bevacizumab beyond disease progression after first-line treatment with bevacizumab plus chemotherapy in advanced nonsquamous non-small cell lung cancer (West Japan Oncology Group 5910L): an open-label, randomized, phase 2 trial. Cancer. 2016;122:1050-9.
33. Kawaishi M, Fujiwara Y, Fukui T, Kato T, Yamada K, Ohe Y, et al. Circulating endothelial cells in non-small cell lung cancer patients treated with carboplatin and paclitaxel. J Thorac Oncol. 2009;4:208-13.

34. Bertolini F, Mancuso P, Shaked Y. Circulating endothelial cells as biomarkers for patients receiving bevacizumab. Lancet Oncol. 2011;12:217-8.

35. Roodhart JM, Langenberg MH, Vermaat JS, Lolkema MP, Baars A, Giles RH, et al. Late release of circulating endothelial cells and endothelial progenitor cells after chemotherapy predicts response and survival in cancer patient. Neoplasia. 2010;12:87-94.

36. Bidard FC, Mathiot C, Degeorges A, Etienne-Grimaldi MC, Delva R, Pivot X, et al. Clinical value of circulating endothelial cells and circulating tumor cells in metastatic breast cancer patients treated first line with bevacizumab and chemotherapy. Ann Oncol. 2010;21:1765-71.

37. Bertolini F, Shaked Y, Mancuso P, Kerbel RS. The multifaceted circulating endothelial cell in cancer: towards marker and target identification. Nat Rev Cancer. 2006;6(11):835-45.

\section{Submit your next manuscript to BioMed Central and we will help you at every step:}

- We accept pre-submission inquiries

- Our selector tool helps you to find the most relevant journal

- We provide round the clock customer support

- Convenient online submission

- Thorough peer review

- Inclusion in PubMed and all major indexing services

- Maximum visibility for your research

Submit your manuscript at www.biomedcentral.com/submit
) Biomed Central 